\title{
Resenha
}

\section{Psicofármacos: consulta rápida}

\author{
Aristides Volpato Cordioli et al. \\ Porto Alegre, Artmed, 2005 ( $3^{\mathrm{a}}$ ed.)
}

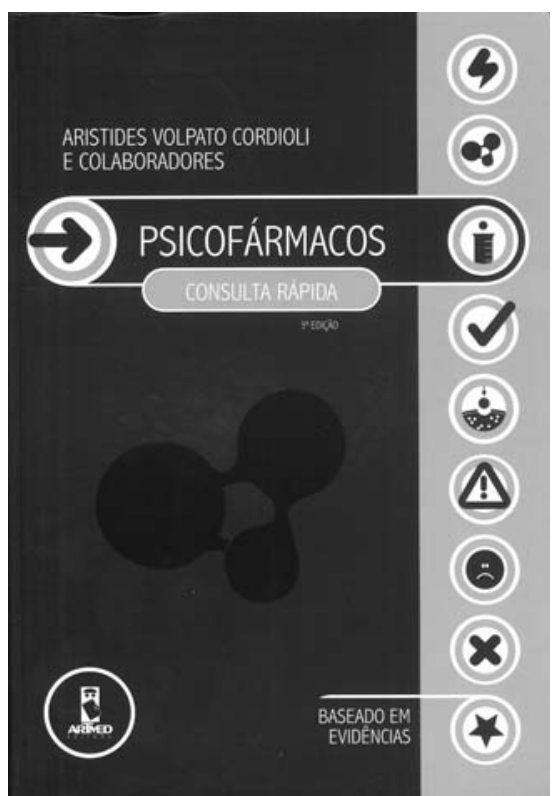

\author{
Dirceu Zorzetto Filho*
}

O lançamento da $3^{\underline{a}}$ edição de Psicofármacos: consulta rápida, de autoria do Prof. Aristides Volpato Cordioli et al., representa um acontecimento pouco comum entre as publicações na área da saúde mental: a continuidade e a expansão de um trabalho de "garimpagem na coleta e na ordenação das informações", como o próprio organizador o definiria na $1^{\text {a }}$ edição do livro. Inicialmente com 316 páginas, com a ajuda de seus colaboradores, Psicofármacos: consulta rápida chega à sua 3a edição dobrando o número de páginas e envolvendo três dezenas de colaboradores. Como se ressalta no prefácio dessa edição, nos últimos 4 anos surgiram mais de duas dezenas de novos medicamentos e mais de uma centena de novos produtos comerciais, aí incluídos os genéricos. Desnecessário salientar a importância e o desafio envolvido no trabalho de atualização dessas e de outras informações pertinentes à área.

O livro mantém quase a mesma estrutura da $2^{a}$ edição, subdividindo-se em cinco seções. A primeira delas, "Medicamentos: informações básicas", traz informações sobre a

\footnotetext{
* Professor, Universidade Federal do Paraná.
}

farmacocinética e modo de usar, farmacodinâmica e mecanismos de ação, reações adversas e efeitos colaterais, indicações, contra-indicações, intoxicação, situações especiais, dados laboratoriais e precauções relacionadas a mais de 130 medicamentos psicotrópicos. Alcança o objetivo de manter-se atualizado com o lançamento de novos produtos, novas aplicações de drogas já conhecidas, assim como suas interações farmacológicas. A segunda seção, "Tratamentos farmacológicos: algoritmos", propõe uma seqüência de procedimentos e alternativas no uso de psicofármacos no tratamento da depressão maior e distimia, transtornos do espectro bipolar do humor, esquizofrenia, transtorno de pânico, transtorno obsessivo-compulsivo, fobia social, transtorno do déficit de atenção e hiperatividade e insônia. Inclui também um capítulo sobre o uso de psicofármacos durante a gestação e a lactação e outro sobre eletroconvulsoterapia. A terceira seção, "Efeitos colaterais e seu manejo", contempla uma das condições mais importantes da prática clínica, determinante em muitas ocasiões: a eficiência do tratamento adotado. "Interações medicamentosas", a quarta seção do livro, apresenta um crescimento considerável no número de informações relacionadas aos 
mecanismos de interação droga-droga, enfatizando as interações potenciais e, quando possível, orientando quanto aos ajustes necessários para se assegurar uma melhora nos pacientes. A última seção, "Psicofármacos em doenças e problemas físicos", contempla as indicações e contra-indicações do uso de psicofármacos em cerca de 70 daquelas condições caracterizadas como comorbidades clínicas.

As páginas iniciais do livro mostram imagens coloridas de várias apresentações comerciais dos medicamentos, tornando fácil sua identificação para profissionais e pacientes.

Title: Review of the book entitled Psicofármacos: consulta rápida

Título: Reseña del libro Psicofármacos: consulta rápida

E-mail: dzorzetto@terra.com.br

Copyright (C) Revista de Psiquiatria do Rio Grande do Sul - SPRS 